\title{
Influence of acid etching on shear strength of different glass ionomer cements
}

\author{
Carolina Carvalho Bortoletto', Walter Gomes Miranda Junior ${ }^{2}$, Lara Jansiski Motta ${ }^{3}$, Sandra Kalil Bussadori ${ }^{4}$
}

'Master's degree student in Rehabilitation Sciences, University Nove de Julho, São Paulo, SP, Brazil

${ }^{2}$ Department of Dental Material, School of Dentistry, University of São Paulo, São Paulo, SP, Brazil

${ }^{3}$ Department of Pediatric Dentistry, University Nove de Julho, São Paulo, SP, Brazil

${ }^{4}$ Department of Rehabilitation Sciences, University Nove de Julho, São Paulo, SP, Brazil

\begin{abstract}
Aim: To assess the influence of dental etching on the shear strength of different glass ionomer cements. Methods: The crown of 60 bovine incisors was prepared to obtain a flat, smooth surface, were attached to a PVC tube and randomly divided into six groups: Group 1 - Riva Self Cure without etching; Group II - Riva Self Cure with pre-etching; Group III - Maxxion R without etching; Group IV - Maxxion R with pre-etching; Group V - Ketac ${ }^{\mathrm{TM} M o l a r}$ Easymix without etching; and Group $\mathrm{VI}-\mathrm{Ketac}^{\mathrm{TM} M o l a r}$ Easymix with pre-etching. Etching was performed with $10 \%$ polyacrylic acid for $30 \mathrm{~s}$. A standardizing device was used for preparation of the test specimens (SBS Test Method). Following preparation, the specimens were stored in distilled water at $37^{\circ} \mathrm{C}$ for $24 \mathrm{~h}$. The shear test was performed on a Kratos universal testing machine at a crosshead speed of $0.5 \mathrm{~mm} / \mathrm{min}$. The specimens were then viewed under a stereomicroscope at a magnification of $x 90$ for analysis of fractures. Results: The results revealed that pre-etching increased the shear strength of Riva glass ionomer cement (SDI) alone, whereas no statistically significant differences were found with regard to the other materials tested. Conclusions: Pre-etching with $10 \%$ polyacrylic acid for $30 \mathrm{~s}$ increased the shear strength of Riva glass ionomer cement.
\end{abstract}

Keywords: glass ionomer cement, shear strength, dentin.

\section{Introduction}

Received for publication: November 09, 2012 Accepted: February 04, 2013

Correspondence to: Carolina Carvalho Bortoletto Rua Rui Barbosa, 133 - 134 Bairro Santo Antônio - CEP: 09530-240

São Caetano do Sul, SP - Brasil Phone: +551142251500 E-mail: carolbortoletto@ig.com.br
Glass ionomer cements have been commonly used in different dental procedures in recent decades ${ }^{1-4}$. These materials offer advantages such as physiochemical adhesion to the dental structure, biocompatibility, the release of fluoride for a long period of time, a thermal expansion coefficient similar to that of teeth and ease of use $^{5-6}$. Despite these properties, glass ionomer cements have limitations, such as low diametral tensile and compressive strength and consequent low border strength as well as their considerable sensitivity to contraction and infiltration, especially in the first moments following placement in the oral cavity ${ }^{6-7}$.

Strong, durable adhesion between the restorative material and tooth is essential, as the adequate adaptation of the material reduces microleakage, pulp irritation and risk of caries recurrence ${ }^{8}$. Shear bond strength tests are the method of choice in the assessment of restorative materials, especially traction and shear strength tests ${ }^{9-10}$. The difficulty of performing a strength test in the oral cavity has led most researchers to the use of extracted teeth ${ }^{9}$. Bovine teeth are often employed for this purpose due to the similarities to human teeth in the results achieved in comparison to the use 
of teeth from dogs or goats ${ }^{11-13}$. Despite divergent opinions regarding the reliability of laboratory tests for the assessment of the clinical performance of restorative materials, such tests indeed achieve a very good correlation with clinical performance, thereby justifying their use ${ }^{14}$.

A number of studies have demonstrated that the treatment of the material in the oral cavity increases the bond strength of the cement to dentin. However, other studies suggest that there is no need for prior treatment for a glass ionomer cement to adhere to the tooth. Others however report that bond strength can be improved by treating the tooth surface with different solutions ${ }^{15-17}$.

Glass ionomer cements have the capacity to form a chemical bond with the tooth, especially the enamel, which is a more mineralized structure. The adhesion process occurs through the chemical bond between carboxyl groups of polyacids (chelation agents of the restorative materials) and calcium ions in the tooth. Despite this ability, the bond strength of glass ionomer cements is considered low. In order to enhance this strength, the application of a $10 \%$ polyacrylic acid solution is indicated, which removes unwanted residue, alters the wetting capacity and improves the adaptation of the material ${ }^{18-19}$. Polyacrylic acid removes the smear layer and surface contaminants, while altering the surface energy and exposing the mineralized dental structure for the diffusion of the acid and ionic exchanges ${ }^{20}$. However, there are divergent opinions regarding the need or non-need for etching prior to restoration with glass ionomer cement as well as the substances used for this purpose ${ }^{21}$. Considering the increase in the number of restorations carried out with this material, especially following the introduction of the concept of atraumatic restorative treatment, further studies on the use of glass ionomer cement are needed.

With the aim of optimizing working time and increase restoration longevity, the purpose of the present study was to assess the influence of dentin etching on the shear strength of different glass ionomer cements.

\section{Material and methods}

Sixty bovine incisors with a healthy crown free of cracks and enamel fractures were used. The roots were sectioned and the crowns were prepared in such a way as to obtain a surface of exposed dentin approximately $5 \times 5 \mathrm{~mm}$. The specimens were then attached to PVC tubes using chemically activated acrylic resin, maintaining the dentin surface exposed. This surface was ground wet onto sandpaper of different grits $(220,320,400$ and 600) until obtaining a flat, smooth surface. The specimens were then randomly divided into six groups, as displayed in Table 1. A standardizing device was used for the preparation of the test specimens (SBS Test Method - SDI - Bayswater, VIC, AU), which allowed similar volume, shape and pressure.

All glass ionomer cements were blended following the manufacturer's instructions. Pre-etching with $10 \%$ polyacrylic acid for $30 \mathrm{~s}$ was performed in Groups II, IV and VI, followed by water-jet cleaning and air-jet drying.

The materials were placed in the cylinder of the standardizing device and submitted a constant force of 0.4 $\mathrm{Kg}$ for $10 \mathrm{~s}$. With the pressure maintained, the materials were stored at $37^{\circ} \mathrm{C}$ for $10 \mathrm{~min}$, after which the pressure was removed and the specimens were stored in distilled water at $37^{\circ} \mathrm{C}$ for $24 \mathrm{~h}$. The specimens were submitted to the shear test on a Kratos universal testing machine at a crosshead speed of $0.5 \mathrm{~mm} / \mathrm{min}$. After the shear test, the specimens were viewed under a stereomicroscope at $\mathrm{x} 90$ for analysis of failure mode. The failure modes were classified as follows: adhesive - when the dental surface was visible in more than $75 \%$ of the area tested (Figure 1); cohesive - when the cement covered more than $75 \%$ of the area tested (Figure 2); and mixed - when the area tested exhibited 25 to $75 \%$ adhesive and cohesive fractures (Figure $3)^{22}$. The non-parametric Kruskal-Wallis test was used for the statistical analysis, with the level of significance set at $5 \%(\mathrm{p}<0.05)$.

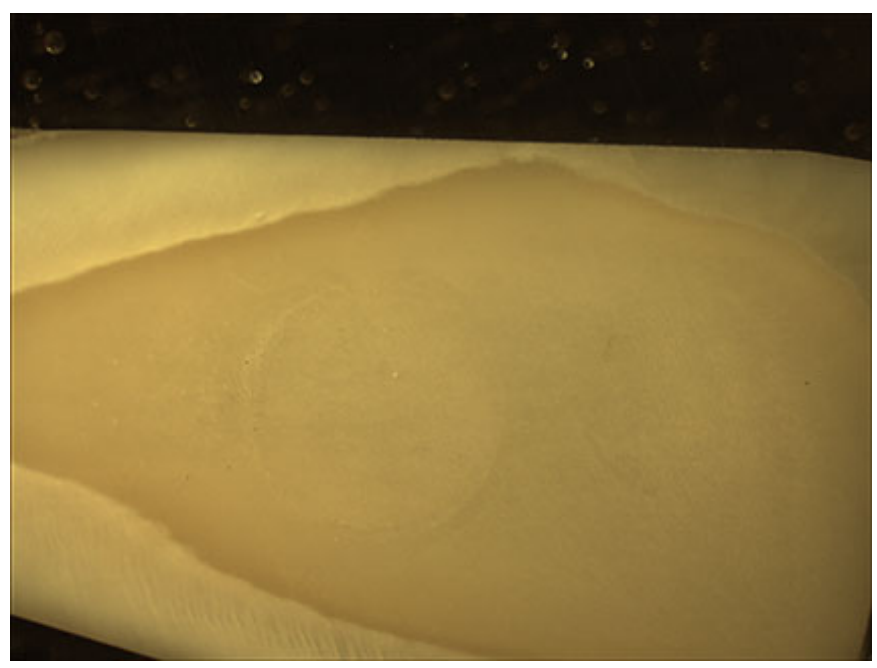

Fig. 1: Adhesive fracture

Table 1: Experimental groups

\begin{tabular}{|c|c|c|}
\hline Group $(n=10)$ & Surface treatment & Restorative material \\
\hline I & No treatment & Riva Self Cure - SDI - Bayswater, VIC, AU \\
\hline$\|$ & $10 \%$ polyacrylic acid for $30 \mathrm{~s}$ & Riva Self Cure - SDI - Bayswater, VIC, AU \\
\hline III & No treatment & Maxxion R - FGM - Joinville, SC, Brazil \\
\hline IV & $10 \%$ polyacrylic acid for $30 \mathrm{~s}$ & Maxxion R - FGM - Joinville, SC, Brazil \\
\hline V & No treatment & Ketac $^{\top M}$ Molar Easymix; - 3M ESPE AG, Seefeld, GE \\
\hline VI & $10 \%$ polyacrylic acid for $30 \mathrm{~s}$ & Ketac $^{\mathrm{TM}}$ Molar Easymix; - 3M ESPE AG, Seefeld, GE \\
\hline
\end{tabular}




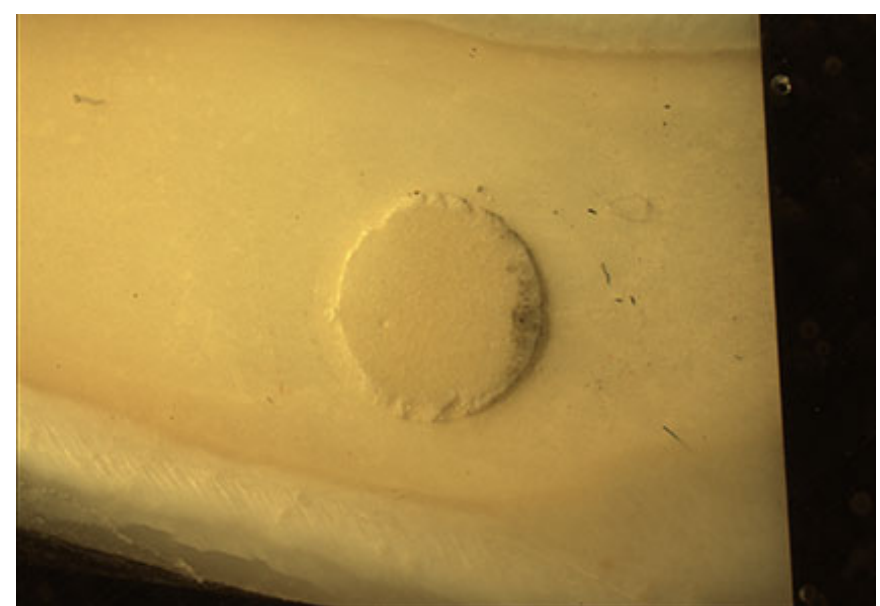

Fig. 2: Cohesive fracture

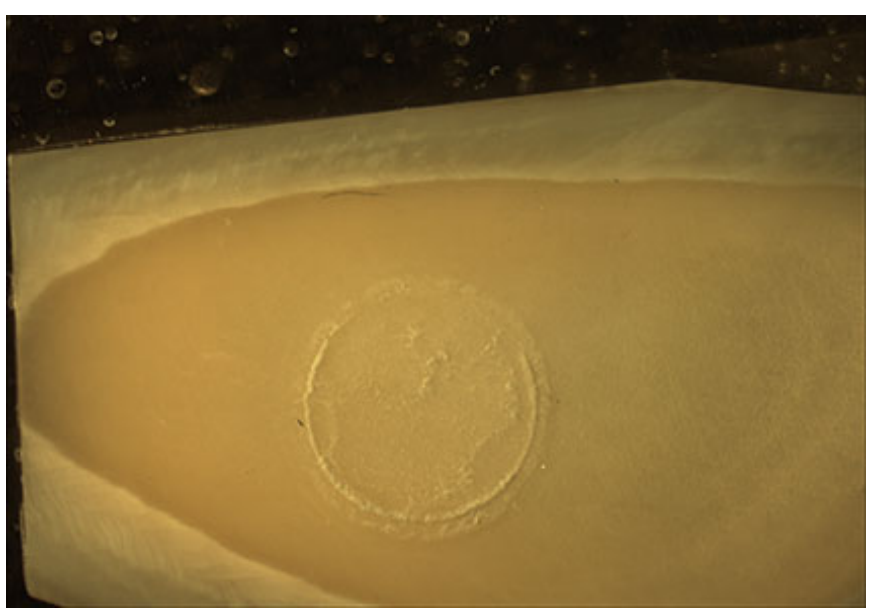

Fig. 3: Mixed fracture

\section{Results}

Mean and standard deviation of shear strength obtained in each group are presented in Table 2. Pre-etching with polyacrylic acid only increased the bond strength in Group II (Riva Self Cure). A number of premature fractures occurred during the tests ${ }^{6}$. In such cases, the shear strength value was considered zero. The results of the microscopic analysis are displayed in Table 3.

\section{Discussion}

Adhesiveness is an important characteristic of glass ionomer cements, as these materials dispense of the need for an intermediate adhesive. The ionomer forms a chemical union with the tooth due to the action of carboxyl groups of polyacids in the calcium found in the apatite of the enamel and dentin. The bond strength is stronger with the enamel due to its greater mineral component ${ }^{6-7,23-24}$. The adhesion mechanism of ionomer materials is the formation of an ionic bond between the liquid component of the cement and the calcium of the hydroxyapatite of the tooth. Moreover, micromechanical adhesion to the collagen fibers exposed on the surface of the dentin may occur following the action of a weak de-mineralizing agent used to remove the smear layer. This occurs more with resin-modified ionomer cements than conventional ionomer cements ${ }^{25}$.

A number of studies have been carried out in the search for improvements to the mechanical properties of glass ionomer cements. However, there is no consensus to date regarding the treatment of the tooth surface in order to ensure better adhesion of the cement. The bond strength of restorative materials is influenced by a number of factors related to the material itself as well as the substrate and even the technique employed. Such factors include the nature of the substrate (healthy or carious dentin), proximity of the pulp, surface roughness, age of the dentin, whether the dental structure is a primary or permanent tooth, dentin permeability, method of carious tissue removal, presence of wrinkles and bubbles in the interior of the material, alterations in the powder/liquid proportions, alterations in the blending and the different treatments the substrate may received, such as acid etching or the use of antimicrobial agents $\mathrm{s}^{7,13}$.

An important factor to consider in the study of glass ionomer cements is the type of fracture displayed. It is very common to find a high rate of cohesive and mixed fractures, which illustrate the cohesion strength rather than the adhesion strength of the material. A standardizing device (SBS Test Method) was used in the present study. This device has a metallic cylinder that envelops the glass ionomer cement until the moment of fracture, the aim of which is to provide greater cohesive strength and thereby allow the assessment of adhesive strength. The high rate of adhesive fractures in the

Table 2: Arithmetic bond strength means and standard deviation for each group

\begin{tabular}{lllllll}
\hline & Group I & Group II & Group III & Group IV & Group V & Group VI \\
Mean & 23.21 & 35.43 & 14.21 & 18.77 & 14.78 & 12.59 \\
Standard deviation & 9.45 & 15.26 & 15.95 & 14.16 & 13.83 & 7.98 \\
\hline
\end{tabular}

No statistical difference was found.

Table 3: Failure modes (\%)

\begin{tabular}{lcccccc}
\hline Failure mode & Group I & Group II & Group III & Group IV & Group V & Group VI \\
Adhesive & 100 & 40 & 60 & 60 & 90 & 100 \\
Cohesive & 0 & 30 & 30 & 30 & 10 & 0 \\
Mixed & 0 & 30 & 10 & 10 & 0 & 0 \\
\hline
\end{tabular}


present study demonstrates the validity of the use of this device.

The statistical analysis of the results demonstrated that pre-etching only improved the bond strength of the Riva Self Cure, whereas no differences were found between etching and non-etching with the other materials. This finding is also made clear by the analysis of fractures with this same material. In Group I, Riva Self Cure was used without pre-etching and $100 \%$ of the failures were adhesive fractures, demonstrating that the material detached from the dentin due to the fact that adhesive strength was less than cohesive strength. In Group II, Riva Self Cure was used with pre-etching and $40 \%$ of the fractures were adhesive, $30 \%$ were cohesive and $30 \%$ were mixed fractures, demonstrating a greater adhesive force, with a consequent greater number of cohesive and mixed fractures. The same did not occur with the Maxxion $\mathrm{R}$ or Ketac ${ }^{\mathrm{TM}}$ Molar Easymix restorative materials.

In this study it was also possible to observe that the pre-etching with $10 \%$ polyacrylic acid increased adhesiveness of Riva Self Cure and Maxxion R. For the Ketac ${ }^{\text {TM }}$ Molar Easymix this treatment decreased the adhesiveness of the material, which may occurred due to the presence of polycarbonic acid and tartaric acid, that may have promoted a reaction with polyacrylic acid. As Self Cure and Maxxion $\mathrm{R}$ present polyacrylic acid in their composition, this reaction does not occur, increasing the material's adhesion. It's important to emphasize that the variation of the adhesion was not statistically significant.

Riva Self Cure had higher adhesion values under both conditions in comparison to the other materials, which may be explained by the fact that this product is a encapsulated cement and its mechanical blending achieves a more homogeneous mixture with less porosity. This creates a larger contact surface between the restorative material and tooth, thereby enhancing bond strength. There is also an increase in cohesive strength due to the reduction in porosity ${ }^{7}$.

It is difficult to compare the results of bond strength obtained in different studies due to the differences in the methodologies employed, such as the substrate used, means of storage and crosshead speed applied during the test. A number of studies report that pre-etching provides no significant difference in the bond strength of glass ionomer cements $^{21,26-28}$. However, others have found an improvement in bond strength when pre-etching is performed ${ }^{15,28-29}$.

Further studies are needed to establish the adhesion mechanisms of glass ionomer cements to carious dentin tissue and determine the best manner for enhancing this adhesion, especially in the context of the more widespread employment of atraumatic restorative treatment.

The results of the present study revealed that preetching with $10 \%$ polyacrylic acid for $30 \mathrm{~s}$ only increased the shear strength of the Riva glass ionomer cement, whereas no statistically significant differences were found between the previously etched and non-etched groups with regard to Maxxion R or Ketac ${ }^{\mathrm{TM}}$ Molar Easymix.

\section{References}

1. Blatt JA, Goes FM. Microleakage in cavities prepared on primary and sclerotic dentin restored with resin modified glass ionomer. Rev Fac Odontol Sao Jose Campos. 2001; 4: 61-6.

2. Gateau $P$, Sabek M, Dayley B. In vitro fatigue resistance of glass ionomer cements used in post-and-core applications. J Prosthet Dent. 2001; 86: 149-55.

3. França TRT, Sedycias M, Silva RJ, Beatrice LCS, Silva CHV. Use of glass ionomer cement : a systematic review. Pesq Bras Odontoped Clin Integr. 2010; 10: 301-7.

4. $\mathrm{Ngo} \mathrm{H}$. Glass-ionomer cements as restorative and preventive materials. Dent Clin North Am. 2010; 54: 551-63.

5. Costa CAS, Ribeiro APD, Giro EMA, Randall RC, Hebling J. Pulp response after application of two resin modified glass ionomer cements (RMGICs) in deep cavities of prepared human teeth. Dent Mater. 2011; 27: e158-e170.

6. Choi K, Oshida Y, Platt JA, Cochran MA, Matis BA, Yi K. Microtensile bond strenght of glass ionomer cements to artificially created carious dentin. Oper Dent. 2006; 31: 590-7.

7. Fagundes TC. Influence of ultrasound on the bond strength of glass ionomer cements to dentin. Bauru: Universidade de São Paulo; 2005. 104p.

8. Çehrli CZ, Akca T, Altay N. Bond strengths of polyacid-modified resin composites and a resin-modified glass-ionomer cement to primary dentin. Am J Dent. 2003; 16: 47A-50A.

9. Mussolino ZM, Borsatto MC, Turbino ML. Shear bond strength of a sealant using components of na adhesive system. Rev Odontol Univ Sao Paulo. 1998; 12: 389-94.

10. Cardoso PEC, Braga RR, Carrilho MRO. Evaluation of micro-tensile, shear and tensile tests determining the bond strength of three adhesive systems. Dent Mater. 1998; 14: 394-8.

11. Tao L, Pashley DH, McGuckin R. In vivo bond strength : effect of depth and tooth type. J Dent Res. 1990; 69: 285 [abstract 1411].

12. Gray SE, Burgess JO. An in vivo an in vitro comparison of two dentin bonding agents. Dent Mater. 1991; 7: 161-5.

13. Pashley EL, Tao L, Matthews WG, Pashley DH. Bond strengths to superficial, intermediate and deep dentin in vivo with four dentin bonding systems. Dent Mater. 1993; 9: 19-22.

14. Chain MC, Chain JB, Leinfelder KF. Hybrid glass-ionomer cements. Dentin bond strength and bondin mechanism. Using electron microscopy. RGO. 2000; 48: 42-9.

15. Powis DR, Folleras T, Merson SA, Wilson AD. Improved adhesion of a glass ionomer cement to dentin and enamel. J Dent Res. 1982; 61: 1416-22.

16. Raggio DP, Sonego FG, Camargo LB, Marquezan M, Imparato JC. Efficiency of different polyacrilic acid concentrations on the smear layer, after ART technique, by Scanning Electron Microscopy (SEM). Eur Arch Paediatr Dent. 2010; 11: 232-5.

17. Castro MFS, Costa JF, Costa EL, Padilha LN, Lopes FF. Effect of chlorhexidine on the adhesion of glass ionomer cement used in atraumatic restorations, using microleakage test. RGO. 2010; 58: 167-71.

18. Van Meerbeek B, ALE. Buonocore memorial lecture. Adhesion to enamel and dentin : current status and future challenges. Oper Dent. 2003; 28 : 215-35.

19. De Munck J, AL E. A critical review of the durability of adhesion to tooth tissue : method and results. J Dent Res. 2005; 84: 118-32.

20. Cunnigham MP, Meires JC. The effect of dentin desinfectants on shear bond strength of resin-modified glass-ionomer materials. Quintessence Int. 1997; 28: 545-51.

21. Inoue S, Abe Y, Yoshida Y, De Munck J, Sano H, Suzuki k, Lambrechts $P$, Van Meerbeek B. Effect of conditioner on bond strength of glassionomer adhesive to dentin/enamel with and without smear layer interposition. Oper Dent. 2004; 29: 685-92. 
22. Hibino Y, Kuramochi K, Harashima A, Honda M, Yamazaki A, Nagasawa $Y$, et al. Correlation between the strength of glass ionomer cements and their bond strength to bovine teeth. Dent Mater J. 2004; 23: 656-60.

23. Tanumiharja M, Burrow MF, Tyas MJ. Microtensile bond strengths of glass ionomer (polyalkenoate) cements to dentin using four conditioners. J Dent. 2000; 28: 361-6.

24. Rekha CV, Varma B, Jayanthi. Comparative evaluation of tensile bond strength and microleakage of conventional glass ionomer cement, resin modified glass ionomer and comomer: An in vitro study. Contemp Clin Dent. 2012; 3: 282-7.

25. Tanumiharja M, Burrow MF, Cimmino A, Tyas MJ. The evaluation of four conditioners for glass ionomer cements using field-emission scanning electron microscopy. J Dent. 2001; 29: 131-8.

26. Hinoura KO, Moore BK, Phillips RW. Influence of dentin surface treatments on the bond strength of dentin lining cements. Oper Dent. 1986; 11: 14754.

27. Banomyong D, Palamara JEA, Burrow MF, Messer HH. Effect of dentin conditioning on dentin permeability and micro-shear bond strength. Eur J Oral Sci. 2007; 115: 502-9.

28. El-Askary FS, Nassif MS, Fawzy AS. Shear bond strength of glassionomer adhesive to dentin : effect of smear layer tickness and different dentin conditioners. J Adhes Dent. 2006; 10: 471-9.

29. Glasspoole EA, Erickson RL, Davidson CL. Effect of surface treatments on the bond strength of glass ionomers to enamel. Dent Mater. 2002; 18 : 454-62. 